\title{
Jacques Monod and the Natural Philosophy of Modern Biology. Some Epistemological Considerations
}

\author{
Annibale Fantoli \\ Sophia University, Tokyo
}

"...These atoms move in the infinite void, separate one from the other and differing in shapes, sizes, position and arrangement; overtaking each other they collide, and some are shaken away in any chance direction, while others, becoming interwined one with another according to the congruity of their shapes, positions and arrangements, stay together and so affect the coming into being of compound bodies".

These words, written by Aristotle's famous commentator Simplicius (1), give a summary of the atomistic vision of Democritus - a vision which, although more than 2400 years old, did not cease to exert a deep influence on modern thought, since the Renaissance until today.

It is precisely to the atomism of Democritus that Jacques Monod explicitly refers in his book "Le hasard et la nécessitê" ("Chance and Necessity"), Editions du Seuil, Paris, 1970 (2). Nobel Prize winner (1965) together with A. Lwoff and F. Jacob, for his research work on the genetic code, Monod has taken upon himself the "mission" of divulging a rigid mechanistic interpretation of the phenomenon of life among lay people, starting thereby a heated debate, which does not seem to have subsided yet.

In this article, we do not intend to enter into the details of the strictly scientific exposition which is given, in "Chance and Necessity", about the basic ideas and results of molecolar biology. As Monod himself modestly admits, "This strictly biological part is in no sense original: I have done no more than summarize what are considered established ideas in contemporary science" (p. 13). Even though this "attempt to extract the quintessence of the molecular theory of the code" (ibid.) deserves our full admiration for its qualities of clarity and lucidity, the real originality of the book, its true interest, consists in the "ideological generalizations" that Monod has "ventured to deduce" (ibid.) from the scientific facts which are at hand, and which constitute (as the subtitle of "Chance and Necessity" explicitly indicates) an "essay on the natural philosophy of modern biology".

Our purpose in the present article is to bring into focus the epistemological problems which arise from this "natural philosophy" of Prof. Monod. In the Preface of his book, the French biologist affirms: "The ideological generalizations I 
have ventured to deduce from it (namely, from the molecular theory of the code) are of course my sole responsibility. But I believe that, where they do not exceed the bounds of epistemology, these interpretations would be accepted by the majority of modern biologists" (ibid.). Still, it seems to us that if there is a basic problem which is raised by Monod's book, it is precisely on the level of epistemology. More explicitly, the first thing to be considered is the epistemological principle according to which objective scientific knowledge is considered as the only type of true knowledge (Monod calls it more briefly "objectivity postulate"). To affirm, as Monod does, that the majority of modern biologists would agree to such a principle, does not seem to resolve, but rather to enlarge, the question. Is this "objectivity postulate", which is supposed to be acknowledged by most of the biologists, actually a valid epistemological principle? Moreover, in which sense and to what extent can it be used to construct a "Natural Philosophy" of modern biology?

\section{The "objectivity postulate" and the properties of living beings}

Among the properties of living beings, two are, according to Prof. Monod, particularly worthy of consideration. The first one consists in the fact that living beings are "objects endowed with a purpose or project, which at the same time they show in their structure and execute through their performances" (p. 20). Monod calls this property "Teleonomy", a new name coined (as it seems) in order to avoid the "metaphysical" connotations of the old term "Teleology" or of the even older one, "Finality". The second property is represented by the fact that living beings are "self-reproducing machines", through "their ability to reproduce and to transmit ne varietur the information corresponding to their own structure" (pp. 22-23). Monod calls this property "invariant reproduction" or, more briefly, "invariance".

According to the French biologist, it is "methodologically indispensable to maintain a distinction" between these two properties. A first reason for such a distinction is that "one can at least imagine objects capable of invariant reproduction but devoid of any teleonomic apparatus". (Monod gives, as an example, crystalline structures, although he himself admits that we have there a "level of complexity... very much lower than that of all known living organisms"). A second reason is represented by the fact that "of the two basic classes of biological macromolecules, one, that of proteins, is responsible for almost all teleonomic structures and performances; while genetic invariance is linked exclusively to the other class, that of nucleic acids". Finally, "this distinction is assumed, explicitly or otherwise, in all theories, all ideological constructions (religious, scientific, or philosophical) pertaining to the biosphere and to its relationship to the rest of the universe" (p. 27).

Now, the existence and distinction of these two properties constitutes for 
biology, according to Monod, "a flagrant epistemological contradiction" (p. 30). In fact, from one part, "the cornerstone of the scientific method is the postulate that nature is objective-in other words, the systematic denial that "true" knowledge can be reached by interpreting phenomena in terms of final causes-that is to say, of "purpose" (ibid.). This postulate, for the very fact that it is a pure postulate", is impossible to demonstrate. "For it is obviously impossible-concedes Monod-to imagine an experiment proving the nonexistence anywhere in nature of a purpose, of a pursued end" (p. 31). And yet, this "postulate of objectivity is consubstantial with science, and has guided the whole of its prodigious development for three centuries. It is impossible to escape it, even provisionally or in a limited area, without departing from the domain of science itself" (ibid.). On the other hand, nevertheless, it is the very objectivity of science-adds immediately Prof. Monodthat "obliges us to recognize the teleonomic character of living organisms, to admit that in their structure and performance they decide on and pursue a purpose" (ibid.).

According to the author, any conception of life (scientific, philosophical or religious) supposes necessarily a solution of this "epistemological contradiction". More concretely, there exist-according to Monod-two big classes of solutions. A first one is represented by the solutions that the author classifies under the label of "vitalism" or "animism", which try to resolve the contradiction by sacrifying (consciously or not) the postulate of ojectivity, and attributing a fundamental function to teleonomy. In other words, all the phenomena of life should be considered as guided by a "teleonomic principle", of which those phenomena would be but the manifestation. Prof. Monod sees in such a position a survival of the "anthropocentric illusion", which today assumes a new form: man seen as the "natural heir, awaited from time immemorial" (p. 47) of the entire universe in evolution (3).

A second class of solutions maintains, on the contrary, the postulate of objectivity even in the case of living beings, asserting that the deterministic mechanism (the "invariance") precedes causally the teleonomy. To this class belongs the "selective (or synthetic) theory" of which Monod himself is a supporter. According to the French biologist, it is only this theory which allows a satisfactory solution of the problem. The central part of "Chance and Necessity" contains the "proof" of this thesis, founded on the results of molecular biology, to which Monod has made a relevant contribution.

Before considering the meaning and value of such a "proof", we would like to make some remarks on the "objectivity postulate", that Monod so strongly affirms to be the foundation of modern scientific epistemology.

First of all, let us remark the fact that at the end of the first chapter of "Chance and Necessity" Monod (as we have already seen) acknowledges that it is 
the very postulate of objectivity which obliges us to admit teleonomy as an objective property of living beings. Up to this point, therefore, (namely given the fact that we do not possess yet a demonstration of the causal priority of one of the two properties to the other), we must suppose that invariance and teleonomy are still on the same level. Now, Prof. Monod starts building up his "proof" on the causal priority of invariance to teleonomy from chapter 3 on. Chapter 2 is a sort of "ideological intermezzo", being consecrated to the consideration of the various types of "vitalisms" and "animisms", which are often criticised very severely (4). This sharp criticism (already implicit in the use of the term "animism"), which precedes the "proof" of the opposite thesis, though finally depending on it, seems to us methodologically not justifiable, at this point of the book.

This is not (in our opinion) a mere pedantic remark. Actually, in spite of all the affirmations to the contrary made by Prof. Monod, teleonomy has not a full citizenship in the domain of his epistemology. Monod's affirmation-according to which scientific method is founded on the "systematic denial that 'true' knowledge can be reached by interpreting phenomena in terms of final causes, that is to say, of 'purpose',, (p. 30)-is a far too precise statement to allow any exception. If then, immediately after, the author admits the objective character of teleonomy, this admission should not deceive us. We are in fact confronted here with a concession which puts us before an epistemological contradiction. Now, in the "cartesian" science of Prof. Monod there is no room for real and definitive contradictions. One can therefore even a priori be sure that such a contradiction will be overcome, and moreover (what matters even more) that it will be overcome by showing that teleonomy is not an original, fully independent property, but that, on the contrary, it originates from the deterministic mechanism of invariance, and finally from the mere interplay of chance. In fact, only "chance and necessity" have a real and definitive right of citizenship in scientific epistemology, at least according to Prof. Monod. This means that, even before giving his demonstration, the author is sure that teleonomy- at least in the sense of an independent, original finalism-can not exist. It is just for this reason that Prof. Monod feels he is authorized to criticize vitalism" and "animism" right from chapter 2 . The biologic considerations which follow are not, therefore, a "proof", but rather a "counter-proof", a "confirmation" of what was already necessarily implied in the postulate of objectivity.

Let us consider now this postulate. Its meaning is (as Monod himself explains) "that the systematic confrontation of logic and experience is the sole source of true knowledge" (p. 154). But what is meant here by "logic" and "experience"? (5). Obviously, if "logic" should be taken as the pure formal coherence between the propositions which the scientist establishes and the deductions that he makes, and if "experience" should indicate nothing more than the mere totality of sensations and feelings, the "systematic confrontation of logic and experience" 
would be rendered impossible. This "confrontation", in fact, is only feasible when "experience" includes all that of which we may be conscious (such as our mental processes of understanding, judgment and decision), and "logic" implies also the constructive logic which consists in formulating hypotheses starting from experience, and in verifying them by coming back to experience. If this is the case, what will then remain of the supposedly pure objectivity of science? "What Monod does not seem adequately to advert to, is the role of the human subject in propounding and testing what is or may be objectively true. It is, after all, conscious human subjects who have constructed the scientific world-view by asking questions about the world, by formulating hypotheses about it, and by judging that there are grounds for thinking that each hypothesis so formulated is probably true or probably false" (6).

In the systematic confrontation of logic and experience, the fact that subjective elements are indissolubly bounded together with the objective ones is confirmed by the whole book of Prof. Monod, as we will try to show. Here it is sufficient to offer as evidence only one point, which however seems to be decisive. The principle of objectivity, as we already know, according to Prof. Monod is a "mere postulate". But then, how can it be justified? The author answers this question at the end of his book. "It is obvious that the positing of the principle of objectivity as the condition of true knowledge constitutes an ethical choice and not a judgment reached from knouledge, since, according to the postulate's own terms, there cannot have been any "true" knowledge prior to this arbitral choice. In order to establish the norm for knowledge the objectivity principle defines a value: that value is objective knowledge itself. To assent to the principle of objectivity is, thus, to state the basic proposition of an ethical system: the ethic of knowledge" (p. 163).

We will take up again this statement later on. Here, it will be sufficient to remark that it eloquently shows how ambiguous is the term "objective", of which Monod makes such a large usage, contrasting it with the "subjectivism" and "anthropomorphism" of the positions that he qualifies as "animistic" or "vitalistic". Actually, what is more "subjective", more "anthropomorphic" than to make the objectivity of science depend on an ethical choice? After all, the "cartesian" distinction between "objective" and "subjective" is rendered far less "clear" and "distinct" than it seemed at the beginning.

The same remark seems to us to hold true concerning the distinction between teleonomic and invariant properties, as we will try to show now.

\section{Invariance and teleonomy}

As we already know, living beings possess two types of essential macromolecules: a) proteins, which are responsible for almost all teleonomic structures 
and performances; b) nucleic acids, which are responsbile for genetic invariance. According to Prof. Monod, it is chiefly the distinction from the chemical point of view of these two types of macromolecules that is at the origin of the distinction between teleonomic and invariant properties. Therefore, in order to prove the mechanistic theory of life (namely, in order to demonstrate that invariance precedes causally teleonomy), Monod considers it sufficient to prove that in the living beings is present a mechanism for the synthesis of the proteins characteristic of each species, which is entrusted to the action of the nucleic acids. In other words, it is sufficient to show that a mechanism of invariance exists, which makes possible the existence and the reproduction of the teleonomic properties. According to Monod, such a proof is supplied by the "molecular theory of the genetic code", which is by now solidly established, at least in its essential points.

We cannot enter here into the technical details of Prof. Monod's proof. We will only mention the fact that the molecular theory of the genetic code is actually able to show how all the "informations" which are necessary for the synthesis of the different amino-acids, and therefore of the different proteins, are contained in the particular structure of the deossiribonucleic acid (DNA) of each living cellule. Moreover, affirms Monod, this mechanism for the "translation of the genetic informations" (in which the other nucleic acid, ribonucleic acid (RNA) plays also an important role) works only in the direction DNA $\rightarrow$ protein, and never viceversa. We have here, insists Prof. Monod, one of the fundamental principles of modern biology, which cannot be called in question. From this it is therefore demonstrated, concludes the author, that invariance (which is linked to the function of DNA) precedes causally the arising of the teleonomic properties, not the contrary (against the thesis of "vitalism" or "animism").

However, do we have here really a conclusive demonstration? Frankly speaking, we do not think so. First of all, the fundamental principle of the irreversibility of the process of translation of the genetic informations (the so-called "Watson' dogma"), upon which the whole thesis is based, could happen to be, after all, not so indisputable as it seems to Prof. Monod. As is well known, H. Temin, of the University of Wisconsin, together with his cooperator Satoshi Mizutani, have shown (1970) that a specific enzyme (which is a protein) stimulates the formation of DNA in cancerogenous virus which possess only RNA. In the same year, Spiegelman, in London, was able to prove that DNA is not always the starting point in the biosynthetic processes. Even if these facts probably are not sufficient, at present, to call in question the irreversibility principle, they show at least how dangerous it is to base deductions of such importance as those made by Prof. Monod, upon a theory to which is given a dogmatic value that such a theory (like any other scientific one) cannot possess.

Secondly, even if the irreversibility principle were to be admitted as an 
indisputable datum, this principle alone is not sufficient to prove the mechanistic thesis. In fact, in order to have a convincing proof, it would be necessary further to show that the distinction between invariance and teleonomic properties, as it is proposed by Prof. Monod, is an adequate distinction, from the logical point of view. It is especially on this point that we feel necessary to express our strongest reservations.

As we have already stressed more than once, according to Prof. Monod this distinction is based chiefly on chemical considerations, namely on the difference between proteins (which are responsible for almost all teleonomic structures) and nucleic acids (responsible for the genetic invariance). Once more, we are confronted here with a very clear cartesian distinction. But here too the clarify is only apparent. Is it really true that the mechanism of transcription of genetic informations is a mechanism of pure invariance, without teleonomy? If the teleonomic structure is characterized by the presence of a "project", are we not obliged to admit that the genetic mechanism is profoundly teleonomic ? Prof. Monod himself seems to admit it implicitly, when he writes: “....we shall define the essential teleonomic project as consisting in the transmission from generation to generation of the invariance content characteristic of the species. All structures, performances and activities contributing to the success of the essential project will hence be called "teleonomic"' (p. 24). We have then, according to the author himself, besides the teleonomic project included in the proteinic structure of living beings, a more ample teleonomic project ("the essential teleonomic project") which encompass the whole process which, starting from the invariance mechanism (and including its very structure), results in the synthesis of proteins. In other words, even Prof. Monod seems to admit that the so-called "pure invariance" of the translating mechanism is at the service of a fundamental, specific teleonomic project. This interpretation appears to be confirmed by other statements of the French biologist. "This apparatus (namely the teleonomic apparatus) is entirely logical, wonderfully rational, and perfectly adapted to its purpose: to preserve and reproduce the structural norm" (p. 30). However, to "preserve and reproduce the structural norm", according to Prof. Monod, is the task of the invariance mechanism. It seems, therefore, that the distinction between teleonomic apparatus and invariance mechanism is not a distinction logically adequate. This seems confirmed by Prof. Monod's own words, when he affirms: "(proteins are) responsible for almost all teleonomic structures ..." (p. 27). According to sound logic, "almost all" implies: "not absolutely all". Where, then, is to be found the cause of the other teleonomic properties? Prof. Monod himself seems to forget his clear-cut distinction, when he writes: "Certain DNA structures play a role that must be considered teleonomic" (p. 52, note 1).

It is apparent, then, that the attempt to deduct teleonomy from invariance 
does not lead to convincing results, for the very reason that teleonomy seems to be present and active within the "rigidly deterministic" invariant mechanisms themselves. Even more, teleonomy seems to transcend these mechanisms, from which it is supposed to be born: "... in a very real sense the organism effectively transcends physical laws - even while obeying them - thus achieving at once the pursuit and fulfilment of its own purpose" (p. 81). "Physical laws": Are not precisely these physical (and chemical) laws and only these responsible for the determinism of invariance? How then could the invariance mechanism be the cause of a structure (the organism) which transcends these laws? The question is the more important because, as we shall see later, Prof. Monod does not admit a qualitative difference among the different levels of organization of material structures.

With the preceding remarks, we do not pretend to have proved, against Prof. Monod, that teleonomy cannot be reduced to, or deduced from, invariance. Such a conclusion would be, at this level of considerations, as little justified as are the conclusions of the author of "Chance and Necessity" in our opinion. We intended only to stress the point that the problem of the relations between teleonomy and invariance cannot be solved at the level of Prof. Monod's epistemology. The "objectivity postulate", on which the French scientist bases all his considerations, does not allow us, in fact, to go beyond the "phenomenological" recognition that teleonomy and invariance are both present and active in the structure of living beings. In order to solve the "epistemological contradiction" which seems to arise from the presence of these two properties, there seems to be needed something different from a mere "scientific proof". This is because - as we think we have sufficiently shown - at the end of such a "proof" we are confronted with the same question as at the beginning. In our opinion, the basic question (to be considered before any other one) is to ascertain if the determinism of the invariant mechanism and teleonomy are really (supposing they are irreducible properties) mutually exclusive. More explicitly, does "Natural Philosophy" require that we see a fundamental opposition between "mechanism" and "project" (or "finality"), so that we should be obliged to choose one as foundation or cause of the other?

It is an undeniable fact that modern science, from the Renaissance up till today, progressed along this direction of thought. The consideration of finalism, teleology, has been always more interdicted by the scientist. The ideal of the "objective knowledge" as it is understood within the frame of the new experimentaldeductive science, requires us to think only in terms of deterministic mechanism. At first, the scientist does not deny finality: he only leaves it to the consideration of the metaphysician. It is only in a further development (which marks a new, more radical step towards "scientism") that finalism and metaphysics are condemned together, as a kind of intellectual obscurantism. Once the animistic "old 
covenant" (as Monod calls it) is destroyed, man is finally able to convert himself from the "Darkness" to the "Kingdom" of the true scientific lnowledge, the only knowledge "tout-court". After such a "conversion", the only final and definitive fact which imposes itself on the scientist is rigid determinism-and chance, as we shall see immediately.

Undoubtedly, there were many "animistic" elements within the old finalistic vision of aristotelic-scholastic metaphyscis. Nevertheless, it seems to us that in the necessary and meritorious process of purification from these relics of animism, promoted by modern thought, there was lost also the genuine, profound, and by no means "animistic" sense which finalism had in the old philosophical tradition. In fact, "finalism" (in the original sense of this philosophical term) did not imply, for Aristoltle or Thomas Aquinas, the presupposition of the existence of a "plan" or "project" in nature. Final causality was considered as the complementary aspect of efficient causality, indissolubly bound up with the latter in all processes of natural becoming. In other words, in any causal process, in which a determinate cause produces a determinate effect, we have the aspect of production (efficient causality) and together with it the aspect of determinate production: the cause is seen as dynamically oriented towards the production of this determined effect rather than another one. And this second aspect is precisely what is meant by "final causality". It clearly follows from this that in the old aristotelic-scholastic tradition it would have been contradictory to oppose "determined process" to "finalistic process". When modern science speaks of chemical "affinity", of a tendency which exists in determinate elements to form determined compounds, she pretends to be speaking only of efficient causality. Actually, Aristotle would answer that this claim is mere non-sense, because the very concept of affinity, of determinated reaction, includes final causality as the necessary complementary term of efficient causality.

It is important to notice that in the frame of aristotelic-scholastic philosophy the concept of "plan", "project" does not emerge, at least logically, except in a second moment, namely when the final causality of the single natural agents is seen synthetically, as an ordained whole movement of the entire physical world (hierarchical finality). It is only through this consideration of the dynamism of the world as a whole, that Aristotle and Thomas Aquinas reach the philosophical conclusion that there is a "plan", a "cosmic finality" at work in the universe. And finally, that there must be an Ordinator, a final Cause of all this finalism in nature.

These remarks may serve perhaps to show that the traditional finalistic vision was not, after all, so candidly animistic and anthropocentric, as Prof. Monod seems inclined to suppose. Once more, we do not pretend to have given an answer to oppose to the opinion of the French scientist. Our sole intention has been to stress the fact that ulterior problems do exist, which cannot be ignored, if one 
intends to reach true conclusions. This is particularly so in our present problem: whether determinism ("necessity") and teleonomy might be considered as equally original properties or not. Such a problem, let us say it once more, does not seem to be soluble within the methodological perspective to which Prof. Monod adheres.

\section{Necessity and Chance}

Actually, the deterministic process of invariant reproduction is not the last word in the explanation of the "mystery of life", according to Prof. Monod. Besides necessity, and even more deeply than that, another element exercises its influence in all natural processes: chance. Monod considers the action of chance on two different plans. First of all, we have the plan of vital phenomena, seen in their development from the first living cellule until the highest levels of evolution. The mechanism of reduplication of the living cellule, with all its rigid determinism and exactness, does not escape the fundamental physical law of microscopic alterations. Under exceptional circumstances, one or more nucleotids of DNA can get destroyed, or added, etc. These are completely random, unforeseeable accidents. But, once they are inscribed into the structure of DNA, they will be reproduced in millions of exemplars, thus passing from the field of chance to that of the most inexorable necessity. Each one of such "mistakes", or "mutations" produces a corresponding alteration in the structure of proteins that (as we know) constitute - as a whole - the teleonomic apparatus of living beings. This apparatus, in its turn, reacts as a "filter" towards the "mutations": the only acceptable ones will be those that do not reduce the coherence of the teleonomic apparatus, but rather strengthen it or even (in much more rare instances) enrich it with new possibilities. Finally, selection gives the final judgment about the efficiency of the teleonomic apparatus thus modified.

The phenomenon of evolution of life is thus explained, according to Prof. Monod, by the play of chance elements. "Pure chance, absolutely free but blind, at the very root of the stupendous edifice of evolution: this central concept of modern biology is no longer one among other possible or even conceivable hypotheses. It is today the sole conceivable hypothesis, the only one compatible with observed and tested fact. And nothing warrants the supposition (or the hope) that conceptions about this should, or even could, be revised" (p. 110).

Let us pause for a moment. To infer from the fact of random mutations in the structure of DNA that "pure chance" has to be put "at the very root of the ....edifice of evolution" seems to be a conclusion exceeding by far the scientific premises. First of all, what is meant here by the word "pure chance"? The most radical interpretation of it would be to assert (as Monod himself seems to be inclined to do) that "a mutation is in itself a microscopic event, a quantum event, to which the principle of incertainty consequently applies - an event which is 
hence by its very nature essentially unpredictable" (p. 112). But this is a controversial interpretation of quantum physics, and Monod himself is aware of it. Thus, he does not insist on it, and prefers to speak of "essential chance" in the sense of "absolute coincidence. . which results from the intersection of two totally independent chains of events" (p. 111). "... even were the principle of uncertainty some day abandoned, it would remain true that between the determination, however complete, of a mutation in DNA and the determination of its functional effects on the plan of protein interaction, one could still see nothing but an "absolute coincidence.... The event would still belong to the realm of "essential chance"" (p. 112). Here, "essential chance" means that the probability of the intersection of the two totally independent chains of events is almost nil. Now, we do not know if Prof. Monod has ever read Aristotle. If not, he would certainly be surprised to hear that Aristotle too speaks of chance events, as the intersection of two independent causal chains. But Aristotle, when speaking of chance, always stresses the fact that in order to have a chance event, one needs to presuppose the existence of determination, causality, in nature. Were all the events in nature "chance events", nothing would happen at all. In fact, the "essential chance" (at least in the latter sense) of which Prof. Monod speaks, presupposes determination: without the invariance mechanism (rigidly deterministic) random mutations would produce simply nothing. Even more, it presupposes teleonomy itself; for, without the "filter function" of the teleonomic apparatus, the evolutive process would get nowhere. Let us sum up: "chance" is indeed one important, indispensable factor, in the phenomenon of evolution. But it is far from being proved that it is the only, or the most fundamental one.

A second plan, more basic, in which we must consider the action of chance, explains Prof. Monod, is that of the origin of the living systems. Among the three steps that can be distinguished a priori in the causal process which might have led to the appearance of the first organisms, the first (formation of nucleotids and amino-acids, or "pre-biotic stage") has a sufficient theoretical and experimental base. The second (formation, starting from the previous stage, of the first macromolecules, capable of their own replication) confronts us with extremely arduous, though not insurmountable, problems, thinks Prof. Monod. The fundamental difficulty, however, lies on the level of the third stage, namely of the "gradual emergence of teleonomic systems which, around replicative structures, were to construct an organism, a primitive cell' (p. 134). The heart of the difficulty is the explanation of the origin of the genetic code and of its translation mechanism. "Indeed (confesses Monod) it is not so much a 'problem' as a veritable enigma. The code is meaningless unless translated. The modern cell's translating machinery consists of at least fifty macromolecular components which are themselves coded in DNA: the code cannot be translated except by products of transla- 
tion. It is the modern expression of omne vivum ex ovo. When and how did this circle become closed? It is exceedingly difficult to imagine" (p. 135).

A clue for the solution of this enigma is given, remarks Prof. Monod, by "the fact that the code is now deciphered and known to be universal" (ibid.). However, according to the present results of molecular biology, the structure of the code seems to be chemically arbitrary. That is, it seems to have to be explained not by chemical (or better, stereochemical) reasons, but only as "the result of a series of random choices which gradually enriched it" (p. 135). If this arbitrariety of the structure of the genetic code should become definitively proved, concludes the author, we would have the consequence (given the universality of this code) that among the countless attempts of elaboration, only one really succeeded. As a consequence, it would be necessary to conclude that the decisive event of life appearing on earth "occurred only once. Which would mean that its a priori probability was virtually zero. This idea is distasteful to most scientists. Science can neither say nor do anything about a unique occurrence" (p. 136). However, remarks Prof. Monod, this repugnance is based, not so much on real scientific reasons, as on the anthropocentric tendency to consider the universe as destined to generate life, and finally man. "We must be constantly on guard against this notion, this powerful feeling of destiny. Immanence is alien to modern science. Destiny is written as and while, not before, happens.... If it (our destiny) was unique, as the appearance of life itself may have been, it was because, before it did appear, its chances of doing so were almost non-existent. The universe was not pregnant with life, nor the biosphere with man. Our number came up in the Monte Carlo game. Is it surprising that, like the person who has just made a million at the casino, we should feel strange and a little unreal?" (p. 137).

Let us pause once more for a moment. Thus, according to Prof. Monod, the "secret of life" is to be found, finally, in the "Monte Carlo game of the blind forces of nature". Once more, we are confronted with the same, decisive question: how can the mairvellous logic and rationality of living systems (which Monod himself stresses so often) possibly be explained as the result purely and solely of chance? Even granted that the origin of life might be explained as a unique occurrence, as the "absolute coincidence" of an enormous number of independent chains of events (7), nevertheless, together with chance, and as a prerequisite of its "working out" we need to admit all the determinism of physico-chemical structures and properties - in a word, all the regularity of nature. Once again, we are brought back to the question: Is all this regularity only of a statistical nature, and are the individual events subject to a radical indeterminism? As we have already seen, Monod himself seems to hesitate to go so far. Not because he is "unwilling to admit, as Einstein did, that "God plays at dice"" (p. 112). For, according to the opinion of Prof. Monod, God does not seem necessary (instead of 
the dice player, it is sufficient to introduce an automatic roulette). The real reason of this hesitation is probably the fact that Monod is aware that there must be an "inferior limit" even in the hypothesis of chance, as Democritus himself was aware of it. In fact, it is impossible to build up a "chance-world" without supposing at least the distinction between "void" and "atom", and attributing a minimum of properties to the latter. Without this basic regularity, the "roulette of nature" could not function; must more, it could not even exist (8).

Thus, we find ourselves confronted with the same question we met at the beginning. How did the order, determinism, regularity possibly originate which we find at all levels of organization of the material world? The "pure and sole chance" is not an answer, but a mere "postulate", which appears to be not less full of contradictions than the postulate of "vitalism" or "animism".

\section{The central nervous system}

The difficulties in the natural philosophy of Prof. Monod become more and more insoluble, as we climb along the evolutive process, to the upper "frontier" of the present biological knowledge. On one hand, Prof. Monod admits that "the part played by teleonomic performances in the orientation of selection becomes greater and greater, the higher the level of organization and hence of autonomy of the organism with respect to its environment" (p. 121). This autonomy shows itself through a capacity of "choice" of a determinate type of behaviour, or through a "desire", which creates new directions in the evolutionary process (9). On the other hand, however, this capacity of choice, the action of this desire, does not imply, according to the author, a "qualitative" difference with reference to the inferior levels of living beings. Everything is explained (or, at least, explainable in theory) by a merely quantitative complication of the mechanism of elementary interactions. In other words, the "logic" which controls the behaviour of living beings, at all their levels, is a univocal, not analogical, logic.

This contradiction between "choice" and "novelty", which appears in the evolutionary process and the uniformity of the "mechanism", becomes particularly evident at the level of man. According to Prof. Monod, the undeniable correlation between the privileged evolution of the nervous system in man, and the development of symbolic language, is to be interpreted in the sense that the latter is "not only the product, but one of the initial conditions of this evolution" (p. 124). Monod clarifies his statement with the following assertions: "appearing very early in our line, the most rudimentary symbolic communication, through its radically new possibilities, was one of those crucial initial 'choices' which decided the future of species by giving rise to a new selective pressure. This selection must have favored the development of linguistic ability and thus of the organ that 
served it, the brain" (p. 124-5). But such an assertion leaves undecided the central point of the question: how can be explained this choice, which opens new directions in the path of evolution? Choice of whom, and for what motive? The question seems to be legitimate, since Prof. Monod contends to explain the enormous wealth of human thought through the analogy with cybernetic machines, and thus, finally, in terms of physico-chemistry. Even the collaborator of Prof. Monod, F. Jacob, confirms the legitimacy of our question, when he writes: "To describe in terms of physics and chemistry a movement of conscience, of sentiment, is a totally different matter. Nothing warrants any hope that we will ever succeednot only because of the complexity, but also because it is known, after Gödel, that a logical system cannot be sufficient to its own description" (10).

In conclusion, Monod's thought seems to oscillate between two classes of distinct affirmations. One includes all the statements in favor of the objectivity of the "teleonomic project": "....the organism effectively transcends physical laws - even while obeying them - thus achieving at once the pursuit and fulfilment of its own purpose" (p. 81). The other one intends to counterbalance the previous assertions, resolving after all (as we have already seen) the spontaneity of the teleonomic reactions into the deterministic invariance of the replicative mechanism, and the homogeneity of the elementary reactions. "Nothing warrants the supposition that the basic reactions are different in nature at different levels of integration" (p. 140).

However, as we have tried to show, invariance seems to imply necessarily teleonomy. Moreover, the mere fact that the elementary reactions are the same at all levels of integration, does not allow us to conclude at once in favour of a purely quantitative difference among the different levels of living beings, or evenmore radically - among the different levels of organization of matter. The fact that the functioning of the central nervous system is founded on mechanisms which can be entirely analyzed by biochemistry, does not mean necessarily that the intellectual activity of man is reducible to the automatic results of a cybernetic apparatus, though of an enormous complexity. While following the same synthetic theory as Monod, G.G. Simpson shows on this point much more caution: "Life - he writes - is materialistic in nature, but it has properties unique to itself which reside in its organization, not in its materials or mechanics" (11). Structure and mechanism are without doubt a necessary condition for life. But is it also its cause? The question becomes undoubtedly more acute when one considers the highest manifestations of the phenomenon of life.

\section{The ideology of Monod}

The fundamental reason of the "contradictions" which seem to exist in Prof. Monod's thought, is to be sought for, we believe, not at the level of the truly 
scientific assertions, but rather at that of the deductions he thinks to be able to make starting from the results of modern biology. As we have already stressed, these deductions are supported by postulates which go beyond the pure domain of science, belonging rather to that of "ideological generalizations" (12). It is on this last point that we would like to reflect now.

While speaking of the problem which arises from the presence of teleonomy in living beings, Monod writes: "It is the very existence of this purpose, at once both pursued and fulfilled by teleonomic apparatus, that is the "miracle". Miracle? No, the real problem lies at another, deeper level than that of the phenomenon" (p. 30). This admission is extremely significant. Prof. Monod himself admits that the solution of the problem of teleonomy is to be looked for at a deeper level than that of the phenomenon, of the biological laws; namely, at the level of intellectual reflection. As we have seen, this intellectual reflection, as it is proposed by Prof. Monod, has its epistemological foundation on the objectivity postulate, which forbids us to consider teleonomy as an original, independent property. However, it is one thing to assert that the scientific methodology is based on a postulate such as this (13); it is another to pretend that teleonomy has to be excluded as an independent fact from the reality of natural phenomena. This second affirmation goes far beyond the previous one, implying (as it does) that scientific knowledge, with its "objectivity postulate", is the only true knowledge.

Here we are confronted with a statement which is no more scientific, but philosophic (or ideologic, as Monod would prefer to call it). As it is well known, this is the classic assertion of "scientism" (14). And we must admit that rarely had there appeared, especially in the last years, a position of such a radical and uncompromising "scientism".

But how is it possible to justify, on the level of "ideology", the adoption of the postulate of objectivity, as the sole foundation of true knowledge? Monod himself, as we have already remarked, feels the difficulty of such a problem, when he admits that the choice of the postulate goes beyond the realm of knowledge, being, as it is, its foundation. However, the author's claim that it is a matter of "ethical choice", is really satisfactory? In fact, how can a purely ethical choice be "the axiomatic condition of authenticity for all discourse and all action" (p. 164) ? Since an ethical choice of this kind is not the result of a merely arbitrary decision, but "put forward a transcendent value, true knowledge, not for the use of man, but for man to serve" (p. 165), and to which only must be attributed the character of truth and authenticity, there seems to be possible but one conclusion: namely, Monod's "ethic of knowledge" implies in its turn an act of faith - that is to say, the faith that only scientific knowledge can bring us to the truth (and even to an authentic political praxis).

An act of faith, however, being an extra-rational act, cannot be rationally justi- 
fied, nor can it consequently be the basis of a rational answer to the problems brought up by the phenomenon of life. In fact, we have already noticed that the claimed cartesian clarity of Prof. Monod's deductions, far from answering the interrogatives, leaves them fully open. This is, as we have seen, the case of the problem of the connections between invariance and teleonomy, and even more that of the meaning and function which must be given to necessity and chance in nature, or that of the distinction between "spirit" and matter, at the level of man.

Facing the "mystery" which after all remains, we have found ourselves with the interrogative of men of all times, and with the possibility of two types of answers: the one which sees in natural processes, at all levels, the manifestation of a cosmic "order" or "project"; the other which pretends to resolve all the teleonomy of the universe into the action of pure chance and blind necessity. Which of the two is right? If we do not want to reduce such a problem to the opposition of two different types of "acts of faith" (or of "ethics of knowledge"), neither of which can be rationally justified, we must have the courage to ask ourselves whether besides scientific knowledge, there would not possibly exist an ulterior form of knowledge, that of philosophy, at whose level the solution of the "frontier-problems" of human knowledge might be looked for: the problem of the existence of the universe, with its physico-chemical properties; the problem of the birth of life; and finally, the problem of the existence of human thought. These enormously difficult and complex problems cannot be solved within the frame of the "scientism" of Prof. Monod. The author of "Chance and Necessity" would no doubt reject such a "philosophical project" as devoid of any meaning. Paradoxical as it may seem, in the "natural philosophy" of Prof. Monod, there is no place for philosophy, but only for science, its claimed perfect objectivity, and its dialectics of determinism and chance. Chance seems to be the last word concerning all the frontier-problems we have mentioned. "Man at last knows that he is alone in the unfeeling immensity of the universe, out of which he emerged only by chance. Neither his destiny nor his duty have been written down" (p. 167). And yet, even Prof. Monod seems to be not fully satisfied with his answer, since he immediately adds: "The kingdom above or the darkness below: it is for him to choose".

Is it not this the whole problem facing us? Which is the "kingdom"? which is the "darkness"? In spite of all its great merits, "Chance and Necessity" does not seem to us to give a satisfactory answer to such an interrogation. Could it not be said, perhaps, that this inability results from the limits of that democritean philosophy, that Prof. Monod wanted to espouse with so much inflexible coherence? That reminds us of Shakespeare's famous words: "There are more things in heaven and earth, Horatius, than are dreamt of in your philosophy" (15). 


\section{Notes}

(1) Simplicius de Caelo 242, 21. Cfr. G.S. Kirk and J.E. Raven, "The Presocratic Philosophers, Cambridge University Press, 1969, p. 419.

(2) This book, by now translated into the principal languages, appeared recently also in the Japanese version ("Gūzen to hitsuzen," Misuzu Shobo, 1972). While quoting Monod's book in the present article, we will refer to the English translation: "Chance and Necessity" (Transl. Austryn Wainhouse), Collins, 1972, indicating the corresponding page in brackets.

(3) Monod himself admits that the meaning he gives to the terms "vitalism" and "animism" is different from that which is meant in contemporary science and philosophy. More than in the case of "vitalism" (which includes - besides the scientific vitalism of Driesch and Polany - also the "metaphysical" one of Bergson) this is true in "animism", which according to Monod includes such contrasting "world-visions" are the ones of Teilhard de Chardin and of Dialectical Materialism.

(4) Particularly the "animism" of Teilhard (pp. 39-40) and that of Dialectical Materialism (pp. 40-47).

(5) See the penetrating remarks made in reference to it by Hugo Meynell, "Monod's Muddle", The Month, July 1973, pp. 241-243, which have given us the cue for our considerations here.

(6) Ibid., p. 241.

(7) We do not intend to consider here the problem which arises in this connection from probability calculation. The latter has often been used in order to "prove" the practical impossibility of life arising as the result of pure chance. However, such "proofs" have been very often proposed in an over-simplified way. (see for instance Lecomte de Noüy, in his well known book "Human Destiny" and its severe criticism in G.G. Simpson: "This View of Life", Harcourt, 1964, p. 218).

(8) One of the most authoritative supporters of the Synthetic Theory, G.G. Simpson, in the book and passage quoted in the previous note, writes: "No one, at least certainly no scientist, ever supposed that any natural event occurs entirely by chance. Ours is, we believe, a lawful universe". An ulterior consideration could be made concerning the real implications of quantum physics. Monod seems to see in it no more than the affirmation of a radical indeterminism, and consequently of pure "chance" events. But is there really only that? For instance, Pauli's exclusion principle seems to impose, at the very level of elementary perticles, the idea of a physical system as a structured activity, from which one could go so far as to affirm the existence of teleonomy at the level of quantum physics itself. Such an affirmation would seem, no doubt, scandalous to Prof. Monod - completely obvious, on the contrary, to the old metaphysicians. It's not because they were "animists", but because, as we tried to show, they saw the whole of natual dynamism (from the first levels of structuration of matter till man) as implying necessarily both teleonomic and efficient causality (as complementary aspects of the same dynamism). We wish to express here our thanks to Prof. Errol E. Harris, of Northwestern University, for the suggestions he gave to us (on this point of the teleonomic interpretation of Quantum physics) in his communication "Mechanism and Teleonomy" at the World Congress of Philosophy in Varna (1973).

(9) Monod writes (p. 122): "In the evolution of certain groups one observes a general tendency, maintained over millions of years, towards the apparently oriented development of certain organs; this fact shows how the initial choice of a certain kind of behaviour....sets the species on the road to a continuous perfecting of structures and performances which support this behaviour". And a little later: "It is therefore correct to say that sexual drive - or better still, desire - created the conditions under which many magnificant plumages were selected". 
(10) F. Jacob, "La Iogique du vivant," Gallimard, 1970. p. 337. Monod himself is aware of the difficulty, when he writes: "A logician might remind the biologist that his efforts to "understand" the complete functioning of the human brain are doomed to fail, since no logical system can produce an integral description of its own structure" (p. 137). But when he tries to get rid of the difficulty, remarking that "this warning would be somewhat inappropriate, considering how far we still are from the ultimate borderline of knowledge" (ibid.), the question inevitably arises: what is meant here by "ultimate borderline" ("frontière absolue")? If the phenomenon of knowledge (especially of auto-conscience) is a limit-phenomenon, an absolute limit, this would seem to imply that a pure explanation in terms of physico-chemistry, however further deepened, will always remain on this side of that limit. This would be in accordance, we think, with the meaning of Gödel's theorem. If on the contrary, as it seems more probable, by "ultimate borderline" Monod means a frontier which is absolutely impossible to cross at the present stage of our knowledge, but fordable in theory (once the logic of bio-molecular cyhernetics will be finally understood), then the difficulty raised by Prof. Jacob would keep all its strength.

(11) G.C. Simpson, "The meaning of Evolution", Yale Univ. Press, 1950, pp. 291-292.

(12) Prof. Monod affirms that the "postulate of objectivity" belongs to the field of science, not of the ideological generalizations, which are the result of a further effort of reflection. But we think to have sufficiently shown that if there is a clear "ideological" position, in Monod's thought, this is to be found first of all at the epistemological level of the "objectivity postulate", as it is understood and used by the French biologist.

(13) Perhaps not all the contemporary scientists would agree on this point, we believe.

(14) More exactly, of the "scientism" of last century, to which many contemporary biologists (like Monod) seem to be far nearer than the majority of physicists. See for instance W. Heisenberg, in "Physics and Beyond", Harper and Row, 1971.

(15) Shakespeare, Hamlet, Act I. 